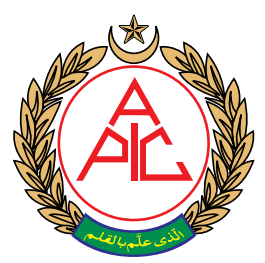

${ }^{1}$ Atatürk Training and Research Hospital, Üniversiteler Mh., 06800 Çankaya/Ankara, (Turkey) ${ }^{2}$ Department of Anesthesiology and Reanimation, Faculty of Medicine, Turgut Ozal University, Ankara 06510, (Turkey)

${ }^{3}$ Private Konak Hospitals. Yenişehir Mahallesi, Demokrasi Cd. No:44, 41100 İzmit/Kocaeli, (Turkey)

${ }^{4}$ Department of Biochemistry, Turgut Ozal University School of Medicine, Ankara 06510, (Turkey)

${ }^{5}$ Department of Anesthesiology and Reanimation, Balıkesir Public Hospital, Balıkesir, (Turkey)

${ }^{6}$ Private hospital, (Turkey)

Correspondence: Hülya

Kaşıkara, Atatürk Training and

Research Hospital, Üniversiteler Mh., 06800 Çankaya/Ankara (Turkey)

Phone: +90 5052712402; E-mail: dr.hulyakasikara@gmail.com Received: 18 January 2019,

Reviewed: 3 February 2019,

Revised:1 May 2019,

Accepted: 9 May 2019.

\section{Evaluation of the effects of esmolol and remifentanil for controlled hypotension application on hemodynamics and oxidative stress parameters}

\author{
Hülya Kaşıkara ${ }^{1}$, Rüveyda İrem Demircioğlu², Muhammet Gözdemir ${ }^{2}$, \\ Safinaz Karabayırlı ${ }^{3}$ Hüsamettin Erdamar ${ }^{4}$, Mehmet Namuslü, \\ Ummügülsüm Yazıc1 ${ }^{5}$, Alper Yüksel ${ }^{6}$
}

\begin{abstract}
Introduction: Anesthesia induced during a surgical intervention, the duration of the surgical intervention, and the surgical intervention itself tend to affect immune functions, resulting in the formation of free radicals in the metabolism. Free radicals can cause postoperative disorders by targeting biomolecules in the cell, such as lipids, carbohydrates, proteins, and DNA. In the present study, we used remifentanil or esmolol to induce a controlled hypotension in patients who were undergoing septorhinoplasty under general anesthesia, and we planned to compare the effect of these agents on hemodynamics and oxidative stress relative to the control group.
\end{abstract}

Methodology: A total of 75 patients aged between 18 and 65 y, ASA I-II, planned to undergo elective septorhinoplasty, were included in this study. Patients were randomly divided into the following three groups: Group R (remifentanil group, $n=25$ ); Group $E$ (esmolol group, $n=25$ ); and Group C (control, $\mathrm{n}=25$ ). Anesthesia was induced with $2 \mathrm{mg} / \mathrm{kg}$ propofol $2 \mathrm{mg} / \mathrm{kg}$, fentanyl 1 $\mu \mathrm{g} / \mathrm{kg}$, and rocuronium $0.6 \mathrm{mg} / \mathrm{kg}$. Immediately after induction, Group R was started loading dose of remifentanil $1 \mu \mathrm{g} / \mathrm{kg} / \mathrm{min}$, followed by infusion at $0.25-0.50 \mu \mathrm{g} / \mathrm{kg} / \mathrm{min}$. In Group E, a loading dose of esmolol $500 \mu \mathrm{g} / \mathrm{kg}$ was given for $1 \mathrm{~min}$, then infusion was continued @ 150-300 $\mu \mathrm{g} / \mathrm{kg}$. A targeted mean arterial pressure (MAP) of $55-65 \mathrm{mmHg}$ was aimed. In Group C, remifentanil was infused at $0.1-0.2 \mu \mathrm{g} / \mathrm{kg} / \mathrm{min}$ until a MAP of $70-100 \mathrm{mmHg}$ was reached. During operation; systolic (SAP), diastolic (DAP) and mean arterial pressure (MAP), heart rate (HR), peripheral oxygen saturation ( $\mathrm{SpO} 2), \mathrm{EtCO}_{2}$ (end tidal $\mathrm{CO}_{2}$ ) were recorded before induction, after induction, after intubation, at 5 -min intervals during the first $30 \mathrm{~min}$, and then at 10-min intervals during the intervention. The amounts of remifentanil and esmolol consumed by the patients during the operation were calculated and recorded. Blood samples that were taken twice, preoperatively and postoperatively, for malondialdehyde (MDA), superoxide dismutase (SOD), total oxidant level (TOL), total antioxidant level (TAL), and oxidative stress index (OSI).

Results: MAP showed a greater decrease starting from the $25^{\text {th }}$ min and $40^{\text {th }}$ min after intubation in remifentanil group and esmolol group respectively, compared to the control group. In the remifentanil and control groups, there was a statistically significant decrease in the postoperative OSI levels compared to the preoperative levels. One the other hand, in the esmolol group, there was no statistically significant difference between the preoperative and postoperative median OSI levels. There was a significant increase in the postoperative TAL of the remifentanil group compared to the preoperative level.

Conclusion: It was observed that during a hypotensive anesthesia induced by remifentanil or esmolol, remifentanil ensured more stable operating conditions in terms of hemodynamics compared with esmolol, and that remifentanil was also superior to esmolol in reducing oxidative stress.

Key words: Esmolol; Remifentanil; Controlled hypotension; General anesthesia; Oxidative stress

Abbreviations: TOL: Total oxidant level; TAL: Total antioxidant level; SOD: Superoxide dismutase; MDA: Malondialdehyde; OSI: Oxidative stress index

Citation: Kaşıkara H, Demircioğlu RI, Gözdemir M, Karabayırlı S, Erdamar H, Namuslu $M$, Yazıcı U, Yüksel A. Evaluation of the effects of esmolol and remifentanil for controlled hypotension application on hemodynamics and oxidative stress parameters. Anaesth pain \& intensiv care 2019;23(2):20-27. DOI: https://doi.org/10.35975/apic.v24i1.1217 


\section{INTRODUCTION}

Antioxidant systems normally work together in unity to protect the cell against toxic effects of free oxygen radicals, which they achieve by keeping the oxidant and antioxidant systems of the organism in balance. Alteration of this balance in favor of oxidants results in the production of inflammatory mediators and free oxygen radicals. ${ }^{1,2}$ The immune system is affected by the anesthesia induced during surgical intervention, the duration of the surgical intervention and the surgical intervention itself, which lead to the formation of free radicals in the metabolism. Free radicals can cause postoperative disorders by targeting biomolecules in the cell, such as lipids, carbohydrates, proteins and DNA. ${ }^{3}$ Combined with operative stress, the applied method of anesthesia may induce an imbalance between the antioxidant defense system and reactive oxygen species. Therefore, the oxidant and antioxidant activities of anesthetic agents may be of clinical importance. The effects of intravenous and volatile anesthetics on oxidative stress parameters have been investigated in different studies; however, the effect on oxidative stress of hypotensive anesthesia applied together with different agents has not yet been investigated..$^{4-6}$ The aim of this study was to evaluate the hypotensive anesthesia method, which was applied using two different agents in terms of lipid peroxidation and antioxidant response through a randomized double-blind study.

\section{METHODOLOGY}

After obtaining approval from the ethics committee of the hospital, our study was performed in patients who had planned elective septorhinoplasty. A total of 75 patients aged between 18 and $65 \mathrm{y}$ who complied with the ASA I-II classification were included in this study.

Patients with coronary artery disease and chronic disease; patients who were morbidly obese, pregnant, or lactating; patients with drug and tobacco addiction; and patients with severe anemia were excluded from this study. Patients whose surgeries lasted for less than $120 \mathrm{~min}$ and more than $300 \mathrm{~min}$ were also excluded from this study. Patients were randomly divided into the following three groups: Group $\mathrm{R}$ (remifentanil group, $\mathrm{n}=25$ ); Group E (esmolol group, $\mathrm{n}=25$ ); and Group C (control group [CG], $\mathrm{n}$ $=25)$. A web application was used for randomization (www.randomizer.org).

After obtaining written informed consents from the patients, they were taken to the operating room without applying a premedication, and infusion was initiated with $-10 \mathrm{~mL} / \mathrm{kg} 0.9 \% \mathrm{NaCl}$ solution via vascular access from a peripheral vein. Standard monitoring was performed for the patients using noninvasive blood pressure (NIBP), ECG, and pulse oximetry. Baseline values were measured and recorded. In all patients, the induction of anesthesia was ensured with IV $2 \mathrm{mg} / \mathrm{kg}$ propofol and $1 \mu \mathrm{g} / \mathrm{kg}$ fentanyl. After achieving muscle relaxation with $0.6 \mathrm{mg} / \mathrm{kg}$ rocuronium, endotracheal intubation was performed. Radial artery cannulation was performed in all patients for invasive arterial pressure monitoring. Anesthesia was maintained through the inhalation of a mixture of 1 MAC sevoflurane and $60 \%$ nitrous oxide mixed with $40 \%$ oxygen. Immediately after induction, Group $\mathrm{R}$ was started on an infusion of $2 \mathrm{mg}$ remifentanil (Ultiva ${ }^{\circledR} 2 \mathrm{mg}$ vial, GlaxoSmithKline) diluted with $100 \mathrm{~mL}$ isotonic (20 $\mu \mathrm{g} / \mathrm{mL}$ ), with an initial loading dose of $1 \mu \mathrm{g} / \mathrm{kg} / \mathrm{min}$ being followed by a dose range of $0.25-0.50 \mu \mathrm{g} / \mathrm{kg} /$ min. In Group E, an initial loading dose of $500 \mu \mathrm{g} / \mathrm{kg}$ esmolol was applied for $1 \mathrm{~min}$, after which infusion was continued at a dose of $150-300 \mu \mathrm{g} / \mathrm{kg}$. In both groups, infusion dose adjustment was performed until the targeted mean arterial pressure (MAP) of 55-65 mmHg was reached. In Group C, remifentanil was also diluted with isotonic and infused at $0.1-0.2$ $\mu \mathrm{g} / \mathrm{kg} / \mathrm{min}$ until $70-100 \mathrm{mmHg}$ MAP was reached. During the operation, systolic arterial pressure, diastolic arterial pressure (DAP), MAP, heart rate (HR), peripheral oxygen saturation $\left(\mathrm{SpO}_{2}\right)$, and end tidal $\mathrm{CO}_{2}\left(\mathrm{EtCO}_{2}\right)$ values were measured and recorded before induction, after induction, after intubation, at 5-min intervals during the first $30 \mathrm{~min}$, and then at 10 -min intervals during the intervention. The amounts of remifentanil and esmolol consumed by the patients during the operation were calculated and recorded. Blood samples were collected in straight tubes from a peripheral vein two times before induction (preoperative) and immediately after extubation (postoperative), and the collected blood samples were centrifuged at $4000 \mathrm{rpm}$ for $10 \mathrm{~min}$ in a centrifuge. Malondialdehyde (MDA), superoxide dismutase (SOD), total oxidant level (TOL), total antioxidant level (TAL), and oxidative stress index (OSI) were examined in the blood samples that were taken preoperatively (preop) and postoperatively (postop).

\section{Power analysis:}

At least 23 subjects needed to be included in each group for testing, at $80 \%$ power and $5 \%$ error level, the statistical significance of a difference of at least 0.40 units of a change in postoperative OSI levels compared with preoperative values between at least two of the groups. The difference of 0.40 units was obtained in both the pilot study and the clinical experience. Sample size calculations were performed using the NCSS \& PASS 2000 statistical package software.

\section{Statistical Analysis:}

Data were analyzed using Statistical Package for 
Table 1: Demographic data

\begin{tabular}{|c|c|c|c|c|}
\hline Variables & Group $\mathbf{R}$ & Group $\mathrm{E}$ & Group C & P-value \\
\hline Age (year) & $31.4 \pm 8.8$ & $30.0 \pm 9.1$ & $33.9 \pm 9.7$ & 0.325 \\
\hline Gender F/M(n) & $12 / 13$ & $13 / 12$ & $8 / 17$ & 0.321 \\
\hline Height (cm) & $169.8 \pm 10.4$ & $171.1 \pm 9.3$ & $170.9 \pm 7.5$ & 0.868 \\
\hline Weight (kg) & $70.0 \pm 14.2$ & $67.2 \pm 13.8$ & $71.9 \pm 13.0$ & 0.480 \\
\hline $\mathrm{BMI}\left(\mathrm{kg} / \mathrm{m}^{2}\right)$ & $24.1 \pm 3.6$ & $22.8 \pm 3.5$ & $24.6 \pm 4.0$ & 0.220 \\
\hline ASA I/II(n) & $19 / 6$ & $17 / 8$ & $21 / 4$ & 0.416 \\
\hline Duration of Anesthesia (min) & $160(100-200)$ & $140(90-200)$ & $130(90-200)$ & 0.051 \\
\hline Duration of Surgery (min) & $145(90-190)$ & $135(85-180)$ & $125(86-185)$ & 0.071 \\
\hline R Consumption (mL) & $60(15-180)$ & - & $26(15-32)$ & $p<0.05$ \\
\hline E Consumption (mL) & - & $90(30-200)$ & - & - \\
\hline
\end{tabular}

Key; F/M: Female/Male. BMI: body mass index, $R=$ remifentanil, $E=$ esmolol, $C=$ control, remifentanil $(1 \mathrm{~mL}=20 \mu \mathrm{g})$. Esmolol $(1 \mathrm{~mL}=40 \mu \mathrm{g})$. Values are shown as mean $\pm \mathrm{SD}$,

median (minimum-maximum), and number of cases (n).

Social Science (SPSS) for Windows 11.5. Normal distribution of the continuous variables was investigated using Kolmogorov-Smirnov test, while homogeneity of the variance was investigated using Levene's test. Descriptive statistics were shown as mean \pm standard deviation or median (minimummaximum) for continuous measurement variables and as case number for nominal variables.

The significance of difference between the groups in terms of mean values was investigated using oneway analysis of variance (one-way ANOVA), while the significance of difference between the groups in terms of median values was investigated using

Table 2: Mean arterial pressure levels readings to monitoring times $(\mathrm{mmHg})$

\begin{tabular}{|c|c|c|c|}
\hline Monitoring Time & Group $\mathbf{R}$ & Group E & Group C \\
\hline Baseline & $96.9 \pm 9.7$ & $100.1 \pm 8.2$ & $100.7 \pm 10.1$ \\
\hline Before induction & $81.6 \pm 14.2$ & $85.1 \pm 11.2$ & $83.5 \pm 10.7$ \\
\hline Intubation & $85.7 \pm 16.6$ & $98.3 \pm 13.6$ & $96.0 \pm 17.8$ \\
\hline 5th min & $76.3 \pm 10.2$ & $85.2 \pm 10.3$ & $89.9 \pm 14.8$ \\
\hline 10th min & $70.3 \pm 9.1$ & $77.3 \pm 9.3$ & $83.8 \pm 15.1$ \\
\hline 15th min & $66.8 \pm 7.8$ & $70.9 \pm 10.0$ & $79.2 \pm 11.6$ \\
\hline 20th min & $63.3 \pm 7.8$ & $67.5 \pm 9.6$ & $76.4 \pm 9.6$ \\
\hline 25th min & $60.7 \pm 3.9$ & $65.5 \pm 7.8$ & $74.4 \pm 6.6$ \\
\hline 30th min & $59.1 \pm 4.5$ & $64.5 \pm 7.3$ & $71.3 \pm 6.6$ \\
\hline 40th min & $59.1 \pm 4.2$ & $61.5 \pm 5.7$ & $71.0 \pm 5.8$ \\
\hline 50th min & $59.0 \pm 3.2$ & $60.8 \pm 5.0$ & $71.6 \pm 5.6$ \\
\hline 60th min & $59.4 \pm 3.9$ & $60.6 \pm 4.1$ & $72.7 \pm 7.3$ \\
\hline 70th min & $59.8 \pm 3.9$ & $59.2 \pm 4.1$ & $72.0 \pm 5.9$ \\
\hline 80th min & $59.7 \pm 2.9$ & $59.0 \pm 4.3$ & $73.0 \pm 6.7$ \\
\hline 90th min & $58.7 \pm 3.4$ & $59.4 \pm 3.8$ & $76.0 \pm 8.8$ \\
\hline 100th min & $59.3 \pm 4.0$ & $60.0 \pm 3.3$ & $74.2 \pm 8.5$ \\
\hline
\end{tabular}

Kruskal-Wallis test. In cases where the results of oneway ANOVA or KruskalWallis test statistics were found to be significant, Tukey's post-hoc HSD test or Conover's nonparametric multiple comparison test was used to determine the conditions causing the difference. Nominal variables were examined using Pearson's chi-squared test. Wilcoxon Sign Test was used to determine whether there was a statistically significant difference between preoperative and postoperative values of the groups in terms of TOL, TAL, SOD, and MDA. Repeated measures analysis of variance was used to evaluate hemodynamic measurements. GreenhouseGeisser test statistics were used to determine whether the group $\times$ time interaction was significant. In cases where the group $\times$ time interaction was found to be significant, the percentage change observed in the successive monitoring times relative to the baseline was compared between the groups.

For the results, $\mathrm{p}<0.05$ was considered as statistically significant. However, Bonferroni correction was performed to check Type I error in all possible subanalyzes.

In terms of demographic data, no statistically significant difference was noted between the groups, except in terms of remifentanil consumption $(\mathrm{p}>0.05)$. The median value of remifentanil consumption in Group $\mathrm{R}$ was $60 \mathrm{~mL}=1200 \mu \mathrm{g}$, while this value was calculated as $26 \mathrm{~mL}=520 \mu \mathrm{g}$ in Group C $(\mathrm{p}<0.05)$ (Table 1$)$.

According to the repeated measures analysis of variance applied to the monitoring of hemodynamic parameters and on the basis of the results of Greenhouse- 
Geisser test statistics, statistically significant differences were noted between the groups in terms of changes in MAP $(F=3.925$ and $p<0.001)$. As these types of analyses only tolerate a maximum of $20 \%$ data loss, the hemodynamic parameters were evaluated up to the $100^{\text {th }}$ minute. In the remifentanil group, MAP showed a greater decrease starting from the $25^{\text {th }}$ minute after intubation compared with the CG $(\mathrm{p}<$ $0.0001)$. In the esmolol group, MAP showed a greater decrease starting from $40^{\text {th }}$ minute after intubation compared to the CG $(\mathrm{p}<0.0001)$. According to the Bonferroni Correction, there was no statistically significant difference between the remifentanil and esmolol groups in terms of the percentage change in the mean blood pressures ( $p>0.0004)$ (Table 2).

According to the Bonferroni correction, no statistically significant difference was noted between the postoperative and preoperative TOL and SOD median values in both the remifentanil and esmolol groups ( $p$ $>0.017$ ), while in the CG, a significant decrease was noted in postoperative TOL and a significant increase in the SOD level compared with the preoperative levels ( $p=0.003$ vs. $p<0.001$, respectively). According to the Bonferroni correction, no statistically significant difference was noted between the postoperative and preoperative TAL median scores in both the remifentanil and esmolol groups ( $p>0.017)$; however, a significant increase was noted in postoperative TAL in the remifentanil group compared with the preoperative level $(p=0.003)$. No statistically significant change was observed between postoperative and preoperative MDA median values in any of the groups $(p>0.017)$. (Table 3: Figure 1)

In the remifentanil and control groups, a statistically significant decrease was noted in the postoperative OSI levels compared with the preoperative levels $(\mathrm{p}=$ 0.003 and $p=0.007)$. On the contrary, no statistically significant difference was noted in the esmolol group between preoperative and postoperative median OSI levels $(\mathrm{p}=0.577)($ Table 3: Figure 1$)$.

\section{DISCUSSION}

In surgical interventions, controlled hypotension during general anesthesia, or hypotensive anesthesia minimizes bleeding and ensures a higher quality of surgical field of view, and thereby shortens the duration of the operation. ${ }^{8,9}$ Antihypertensives or opioid receptor agonists are widely used to this end. All studies conducted on controlled hypotension tend to evaluate intraoperative hemodynamic stability, postoperative recovery, and cognitive functions. ${ }^{7,8,9}$ However, there appear to be no studies in the literature on the oxidative changes in the metabolism caused by hypotension. In the present study, we used remifentanil or esmolol to induce a controlled hypotension in patients who were undergoing
Table 3: Preoperative and postoperative TOL, TAL, SOD, MDA, and OSI levels. [Values expressed as median (minimum-maximum)

\begin{tabular}{|c|c|c|c|}
\hline Variable & Preoperative & Postoperative & p-value ${ }^{\dagger}$ \\
\hline \multicolumn{4}{|l|}{ TOL } \\
\hline Remifentanil & $0.29(0.09-2.51)$ & $0.23(0.05-1.05)$ & 0.022 \\
\hline Esmolol & $0.42(0.10-2.37)$ & $0.23(0.10-1.28)$ & 0.563 \\
\hline Control & $0.21(0.09-1.57)$ & $0.16(0.05-0.27)$ & $0.003^{+}$ \\
\hline \multicolumn{4}{|l|}{ TAL } \\
\hline Remifentanil & $0.90(0.57-1.24)$ & $0.95(0.60-1.25)$ & $0.003^{+}$ \\
\hline Esmolol & $0.98(0.48-1.52)$ & $1.00(0.77-1.54)$ & 0.495 \\
\hline Control & $1.18(0.63-1.58)$ & $1.06(0.57-1.52)$ & 0.055 \\
\hline \multicolumn{4}{|l|}{ SOD } \\
\hline Remifentanil & $2.76(1.55-3.83)$ & $2.60(1.27-4.90)$ & 0.253 \\
\hline Esmolol & $2.52(1.80-3.41)$ & $2.35(1.79-2.99)$ & 0.019 \\
\hline Control & $2.99(1.79-3.45)$ & $4.01(3.05-5.34)$ & $<0.001^{+}$ \\
\hline \multicolumn{4}{|l|}{ MDA } \\
\hline Remifentanil & $\begin{array}{c}54.84(41.94- \\
98.39)\end{array}$ & $\begin{array}{c}58.07(38.71- \\
838.76)\end{array}$ & 0.403 \\
\hline Esmolol & $\begin{array}{c}69.36(50.00- \\
138.72)\end{array}$ & $\begin{array}{c}64.52(53.23- \\
140.33)\end{array}$ & 0.098 \\
\hline Control & $\begin{array}{c}75.81(33.87- \\
158.07)\end{array}$ & $\begin{array}{c}64.52(40.33- \\
191.95)\end{array}$ & 0.166 \\
\hline \multicolumn{4}{|l|}{ Osi } \\
\hline Remifentanil & $0.30(0.11-3.04)$ & $0.21(0.04-1.52)$ & $0.003^{+}$ \\
\hline Esmolol & $0.39(0.11-2.57)$ & $0.21(0.06-1.50)$ & 0.577 \\
\hline Control & $0.18(0.07-1.57)$ & $0.14(0.06-0.29)$ & $0.007^{+}$ \\
\hline
\end{tabular}

+ According to the Bonferroni correction, the results were considered statistically significant for $p<0.017$. TOL: total oxidant level, TAL: total antioxidant level, SOD: superoxide dismutase, MDA: malondialdehyde, OSI: TOL/TAL, Oxidative stress index.

septorhinoplasty under general anesthesia, and we planned to compare the effects of these agents on hemodynamics and oxidative stress relative to the CG (low-dose remifentanil). In our study, when we evaluated each of the three groups in terms of hemodynamics, we observed that the targeted MAP was achieved within a shorter period in the remifentanil group compared with the esmolol group, and we also noted that the remifentanil group was associated with more stable hemodynamics during the operation (Table 2). We also observed greater surgical satisfaction in terms of surgical field of view.

Remifentanil is a clinical anesthetic drug that can activate the N-methyl-D-aspartate receptor. The fact that remifentanil has a single ester structure makes it susceptible to rapid ester hydrolysis by blood and tissue esterases in a similar manner to esmolol. The 
esmolol and remifentanil for controlled hypotension
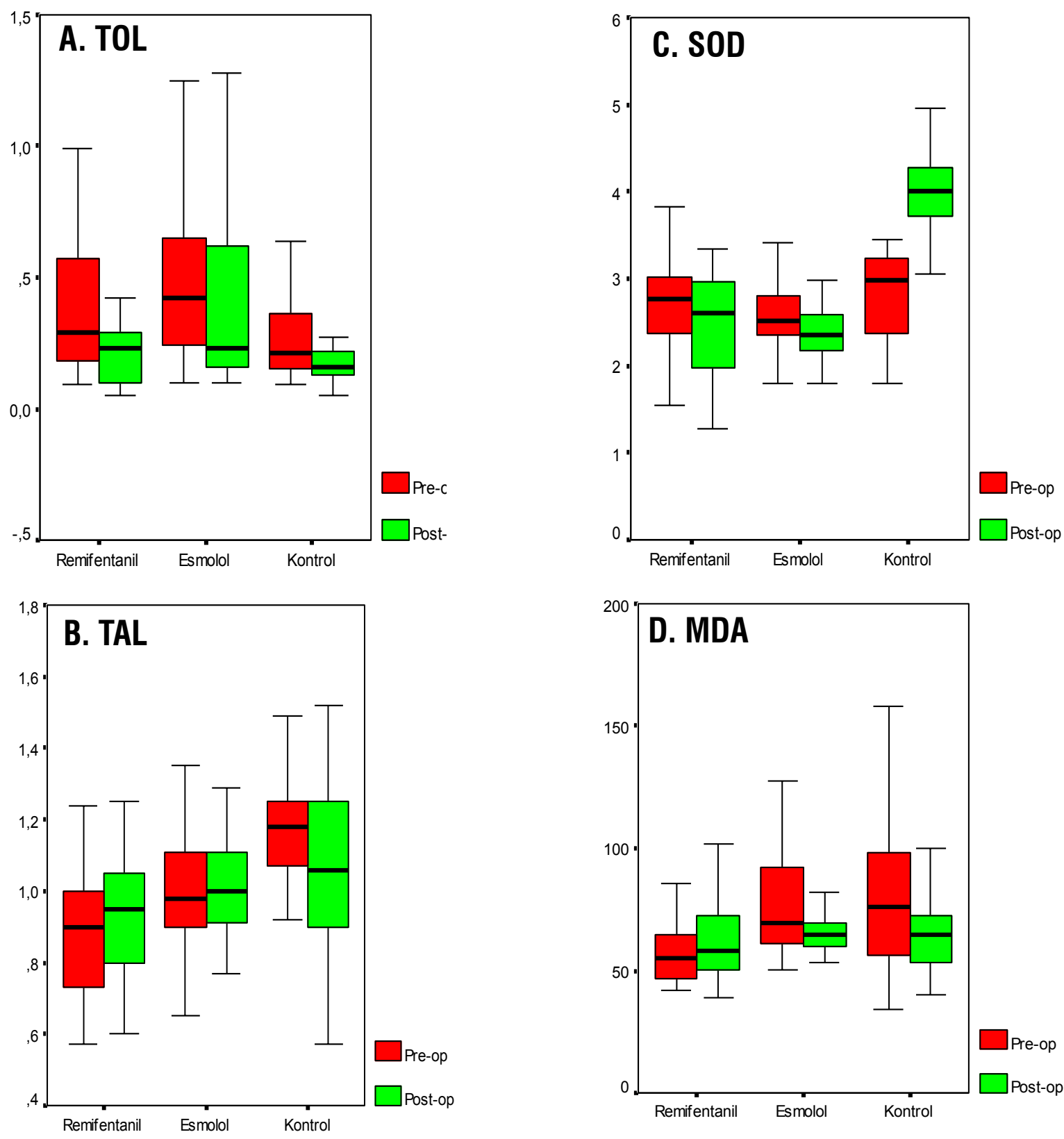

Figure 1: Preoperative and postoperative total antioxidant levels; A. TOL-total oxidant level, B. TAL-total antioxidant level, C. SOD-superoxide dismutase, D. MDA -malondialdehyde, E. OSI -oxidative stress index (TOL/TAL) levels of the groups

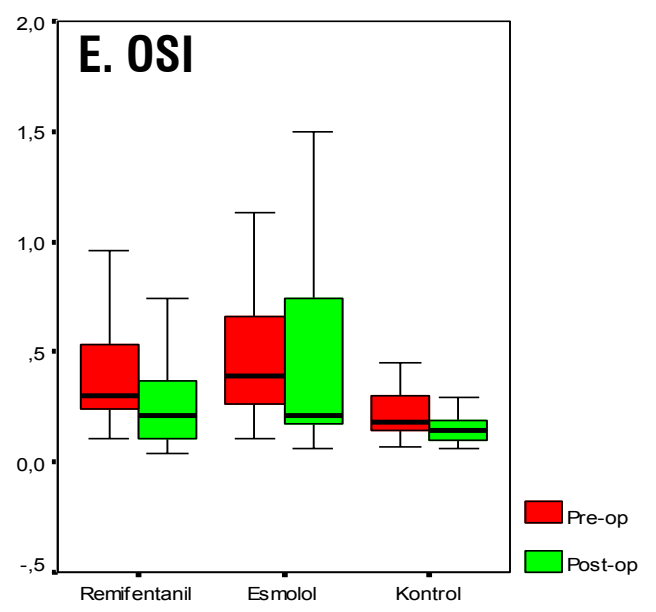


biotransformation is so rapid and complete that the duration of remifentanil infusion has little effect on waking time. The half-life is approximately $3 \mathrm{~min}$, regardless of the duration of infusion..$^{10}$ Remifentanil achieves the highest effect in 1.5 min with a single dose and shows rapid onset of action. It also has a high performance owing to its ability to form a balanced blood-brain barrier rate within a short time. Owing to its rapid rate of clearance, it is an opioid receptor agonist that does not cause any delay in recovery, even when applied at high intraoperative infusion doses. ${ }^{11}$

Hepatic ischemia-reperfusion injury (IRI) caused by free oxygen radicals and inflammatory mediators is one of the most frequently occurring complications in liver transplantation. ${ }^{12}$ In animal studies, remifentanil preconditioning has been shown to reduce IRI by promoting the expression of inducible nitric oxide synthase. Remifentanil inhibits the IL18 signaling pathway and activates antiapoptotic pathways. Remifentanil is one of the most widely used opioids that does not cause any delay in recovery even when administered at a high intraoperative infusion dose. Furthermore, owing to its molecular structure, remifentanil primarily circulates in nonionized areas, and its liposoluble structure helps it in penetrating the blood-brain barrier and reaching a balance in this area. ${ }^{13,14}$ Cui Cui et al. designed an animal study to determine whether remifentanil provides protection against hepatic IRI through the activation of the $\mu$-opioid receptor, and, if so, to determine whether the vagus nerve was involved in this process. In this study, it has been shown that, with hepatic preconditioning, remifentanil provides protection against IRI by activating the central vagus nerve instead of peripheral $\mu$-opioid receptors. ${ }^{15}$

Opioid receptor agonists have been shown to play a role in prevention of brain injury through pharmacological preconditioning. In an animal study conducted by Miao et al., it has been shown that 0.6 $\mu \mathrm{g} / \mathrm{kg} / \mathrm{min}$ remifentanil plays a role in preventing brain damage in rats with preconditioning. ${ }^{16}$ In a study by Zhang et al. performed in 2004, $0.6 \mu \mathrm{g} / \mathrm{kg} /$ min remifentanil preconditioning has been shown to play a protective role against myocardial ischemia/ reperfusion injury. In the above-mentioned study, 40 patients who underwent coronary artery bypass grafting (CABG) were included. Three different infusion doses were selected for administration during the operation to investigate the protection offered by remifentanil within the analgesic dose range defined in the literature. These doses were $0.6,1.2$, and $1.8 \mu \mathrm{g} /$ $\mathrm{kg} / \mathrm{min}$. Studies have shown that the concentration of $\mathrm{S}-100 \beta$ protein increased during CABG, exceeding $0.5 \mu \mathrm{g} / \mathrm{L}$, which indicates a certain degree of brain injury in all patients undergoing CABG. The plasma concentration of S-100 $\beta$ protein decreased only in the $1.8 \mu \mathrm{g} / \mathrm{kg} / \mathrm{min}$ remifentanil group; it was thus shown that the remifentanil preconditioning protection was achieved in a dose-dependent manner. It was observed that preconditioning increased plasma SOD activity, and that the $S-100 \beta$ protein showed a negative correlation with SOD only at the remifentanil dose of $1.8 \mu \mathrm{g} / \mathrm{kg} / \mathrm{min} .{ }^{17}$ Our study evaluated the effect of the controlled hypotension induced by remifentanil and esmolol on the oxidative stress that occurred during the operation. In the remifentanil group (RG), the remifentanil infusion dose was adjusted to achieve a MAP between 55 and $65 \mathrm{mmHg}$, and this corresponded with a dose that was approximately three times higher than the one used in the CG (average remifentanil consumption: RG/CG; $1200 \mu \mathrm{g} / 520 \mu \mathrm{g})$. In the CG, controlled hypotension was induced with a lower dose remifentanil infusion, while a more moderate controlled hypotension was achieved with a MAP of 70-90 mmHg. In these groups, OSI was measured as the most concrete indicator of the oxidative state during the operation. In both the remifentanil and control groups, a statistically significant decrease was noted in the postoperative OSI levels compared with the preoperative OSI levels $(\mathrm{p}=0.003$ and $\mathrm{p}=0.007)$. However, no statistically significant difference was noted in the esmolol group in terms of preoperative and postoperative OSI levels $(\mathrm{p}=0.577)$ (Table 2). When the remifentanil and control groups were compared with the esmolol group, it was observed that esmolol infusion did not have a significant effect in reducing oxidative stress.

Esmolol is a cardioselective $\beta 1$ blocker with rapid onset and short action time. The efficacy of esmolol have been identified in various patients with unstable angina, myocardial ischemia, supraventricular arrhythmia, electroconvulsive therapy, perioperative tachycardia, and hypertension. Different dosage programs have been developed depending on the clinical environment and diagnosis. It is usually intravenously administered for $1 \mathrm{~min}$ with an initial loading dose of $500 \mu \mathrm{g} / \mathrm{kg} / \mathrm{min}$, followed by a continuous infusion of $25-300 \mu \mathrm{g} / \mathrm{kg} / \mathrm{min}$. The half-life of esmolol is $9 \mathrm{~min}$. Its primary side effect, hypotension, can be minimized by careful dosage titration and patient follow-up. Numerous recent studies have shown that in a perioperative setting involving tracheal intubation and extubation, esmolol can be safe and effective, through careful titration, in reducing the incidence of myocardial ischemia. The primary adverse effect of esmolol is usually concomitant hypotension $(0 \%-50 \%)$. The incidence of hypotension increases with doses exceeding 150 $\mu \mathrm{g} / \mathrm{kg} / \mathrm{min}$ and in patients with low basal blood pressure. In case of hypotension, any intervention other than reducing the dose or stopping the infusion is usually not necessary. Symptoms often disappear within 20-30 min after discontinuation of the drug. ${ }^{18,19}$ In our study, the MAP in the esmolol group was reached within a longer time than the RG, and some of the patients experienced hypotension and 
bradycardia. Therefore, more titration was required in the infusion dose of the drug. When the three groups were evaluated in terms of hemodynamics, it was found that the targeted MAP was reached within a shorter time in the RG, and that this group achieved more stable hemodynamics during the operation (Figure 1). In a study conducted by Guan et al. in 2011, stress response and cardiovascular stability were investigated by remifentanil or esmolol infusion in the patients during electro shock therapy procedure performed under anesthesia. Remifentanil was found to be superior to esmolol in sustaining cardiovascular stability and inhibiting a stress response. ${ }^{20}$

Studies have shown that free oxygen radicals contribute to reperfusion injury in myocardial infarction (MI). A prospective study performed by Daqa et al. in 2003 investigated the clinical and antioxidant effects of esmolol in patients with acute MI. All patients who were admitted with acute MI were treated with streptokinase and thrombolysis, after which an esmolol infusion was performed in 15 patients randomly selected among 30 patients, while the remaining 15 patients were recorded as CG. MDA, SOD, and Glutathione peroxidase (GPX) levels were measured and compared in blood samples obtained from the patients at the 0 th, 2nd and, 24th $h$. The antioxidant effect of esmolol was clearly observed with a significant increase in MDA level and GPX's protective effect. ${ }^{21} \mathrm{SOD}$, an enzyme that plays a major role against free oxygen radicals, eliminates free radicals by catalyzing superoxide anions, and plays a protective role in tissues and cells by enhancing the regulatory function of hydrogen peroxide. MDA is the final metabolite resulting from the lipid peroxidation of polyunsaturated fatty acids by free radicals, and hence reflects the activity of free radicals and the degree of cell damage. ${ }^{16}$ In our study, it was found that the level of SOD significantly increased only in the CG. In the RG, the TAL was found to increase significantly. In this study, MDA level did not show any significant change in any of the groups.

\section{CONCLUSION}

The results of our study conclude that during a hypotensive anesthesia induced by remifentanil or esmolol, remifentanil ensured more stable operating conditions in terms of hemodynamics compared to esmolol, and that remifentanil was also superior to esmolol in reducing oxidative stress.

Conflict of interest: Nil

Authors' contribution:

HK, RiD: Contributed to introduction ,method and discussion parts

MG, SK: Contributed to results and discussion parts

HE, MN:_Analyzed biochemicals

UY: Patient monitoring; collection of blood samples from patients

AY: Performed surgical operations 
perspective

\section{REFERENCES}

1. Chopineau J, Sommier MF, and Sautou V. Evaluation of free radical production in an ischaemia-reperfusion model in the rabbit using a tourniquet. $J$ Pharm Pharmacol. 1994; 46(6):51920. [PubMed] DOI: $10.1111 / \mathrm{i} .2042-$ 7158.1994.tb03842.x

2. Halliwell $B$. Reactive oxygen species in living systems: source, biochemistry, and role in human disease. Am J Med. 1991;91(3C):14-22S. [PubMed] DOl: 10.1016/0002-9343(91)90279-7

3. Akkuş i. Serbest Radikaller ve Fizyopatolojik Etkileri. Konya: Mimoza Yayınları; 1995. p.35-96.

4. Allaouchiche B, Debon R, Goudable J, Chassard D. Oxidative stress status during exposure to propofol, sevoflurane and desflurane. Anesth Analg. 2001;93(4):981-5. [PubMed] DOI: $10.1097 / 00000539-200110000-$ $\underline{00036}$

5. Sedlic F, Pravdic D, Ljubkovic M, Marinovic J, Stadnicka A, Bosnjak ZJ. Differences in production of reactive oxygen species and mitochondrial uncoupling as events in the preconditioning signaling cascade between desflurane and sevoflurane. Anesth Analg. 2009;109(2):40511. [PubMed] DOI: 10.1213/ ane.0b013e3181a93ad9

6. Celebi N, Artukoglu F, Dal D, Saricaoglu F, Celiker V, Aypar U. Effect of hypotensive anesthesia on cognitive functions. A comparison of esmolol and remifentanil during tympanoplasty. Saudi Med J. 2007;28(9):1357-61. [PubMed]

7. Gokce BM, Karabiyik L, Karadenizli Y. Hypotensive anesthesia with esmolol. Assessment of hemodynamics, consumption of anesthetic drugs, and recovery. Saudi Med J. 2009;30(6):771-7. [PubMed]

8. Kaygusuz $\mathrm{K}$, Yildirim $\mathrm{A}, \mathrm{Kol} \mathrm{IO}$, Gursoy S, Mimaroglu C. Hypotensive anaesthesia with remifentanil combined with desflurane or isoflurane in tympanoplasty or endoscopic sinus surgery: a randomised, controlled trial. J Laryngol Otol. 2008;122(7):691-5. [PubMed] DOI: 10.1017/S0022215107001545

9. Morgan GE, Mc Graw-Hill, Murray MJ, ed. In Clinical Anesthesiology. Nonvolatile anesthetics. 2002 p:194.

10. Bi XL, You QD, Chen L. Spectral data and structural analysis of remifentanil hydrochloride. Program Pharmac Sci. 2003;26:360-2.

11. Yang LQ, Tao KM, Liu YT, Cheung CW, Irwin MG, Wong GT, et al. Remifentanil preconditioning reduces hepatic ischemia-reperfusion injury in rats via inducible nitric oxide synthase expression. Anesthesiology. 2011;114(5):1036-47. [PubMed]DOI: 10.1097/ALN.0b013e3182104956

12. Zhai $\mathrm{Y}$, Petrowsky $\mathrm{H}$, Hong JC, Busuttil RW, Kupiec-Weglinski JW. Ischaemia-reperfusion injury, in liver transplantation-from bench to bedside. Nat Rev Gastroenterol Hepatol. 2013;10(2):79-89. [PubMed] DOI: 10.1038/nrgastro.2012.225

13. Cannistrà $M$, Ruggiero $M$, Zullo $A$, Gallelli G, Serafini S, Maria M, et al. Hepatic ischemia reperfusion injury: a systematic review of literature and the role of current drugs and biomarkers. Int J Surg. 2016 Sep;33 Suppl 1:S57-70. [PubMed] DOI: 10.1016/j. ijsu.2016.05.050

14. Cui C, Yu F, Yin S, Yang $Y$, Jiao $\mathrm{Y}$, Cheung $\mathrm{C}$, et al. Remifentanil preconditioning attenuates hepatic ischemia-reperfusion injury in rats via neuronal activation in dorsal vagal complex. Mediators Inflamm. 2018;2018:3260256. [PubMed] DOI: $\frac{10.1155 / 2018 / 3260256}{x}$

15. Miao XR, Xiong L, Wang $Q$. Remifentanil preconditioning induces

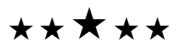

protection against focal cerebral ischemia-reperfusion injury in rats. $\mathrm{J}$ Clin Anesthesiol. 2006;4:277-9.

16. Zhang TZ, Zhou J, Jin Q, Sun YJ, Diao YG, Zhang YN, et al. Protective effects of remifentanil preconditioning on cerebral injury during pump-assisted coronary artery bypass graft. Genet Mol Res. 2014 Sep 26;13(3):765865. [PubMed] DOl: 10.4238/2014. September.26.3

17. Wiest DB, Haney JS. Clinical pharmacokinetics and therapeutic efficacy of esmolol. Clin Pharmacokinet. 2012 Jun 1;51(6):347-56. [PubMed] DOl: 10.2165/11631590-000000000$\underline{00000}$

18. Barbier GH1, Shettigar UR, Appunn DO. Clinical rationale for the use of an ultra-short acting beta-blocker: esmolol. Int J Clin Pharmacol Ther. 1995 Apr;33(4):212-8. [PubMed]

19. Angaran DM, Schultz NJ, Tschida VH. Esmolol hydrochloride: an ultrashort-acting, beta-adrenergic blocking agent. Clin Pharm. 1986 Apr;5(4):288-303. [PubMed]

20. Guan $L$, Guo $X Y$, Li $Q$. Effect of remifentanil or esmolol on stress response during electric shock therapy in psychiatric patients (Article in Chinese). Zhonghua Yi Xue Za Zhi. 2011 Mar 22;91(11):769-71. [PubMed]

21. Daga MK, Chaudhary M, Sharma B, Bhattacharjee J, Ghambhir DS, Arora $\mathrm{N}$, et al. Effect of esmolol on oxidant status and antioxidant activity in acute myocardial infarction. J Assoc Physicians India. 2003 Jul;51:677-80. [PubMed] 